\title{
Risk based decision making in highway slope geometry design
}

\author{
Hasna Aulia Arifani ${ }^{1, *}$ and Widjojo Adi Prakoso ${ }^{1}$ \\ ${ }^{1}$ Department of Civil Engineering, Faculty of Engineering, Universitas Indonesia, Depok, Indonesia
}

\begin{abstract}
Soil uncertainties should be considered in the safety and economic evaluation of geotechnical structures. The impact of uncertainties in risk assessment help engineer in deciding a safer and economically feasible design of geotechnical structures. This paper studies the effect of red clay soil strength uncertainties on the highway excavated slope geometry designs. Different slope geometries are considered: slope angles of 27, 34, 45 and 63 degrees and slope heights of $5 \mathrm{~m}, 10 \mathrm{~m}$ and $15 \mathrm{~m}$. The probabilistic analysis of slope stability is conducted using SLOPE/W to obtain the probability of failure, as well as the failed soil mass volume. The resulting probabilities are used in the quantitative decision making analysis on slope geometries. The Expected Monetary Value (EMV) derived from the construction costs, the repair costs, as well as the highway closure losses for different Levels of Service, is used in the analysis. The decision-making analysis results provide an overview of how the consequences of slope failures determining the decisions made. The consequences of slope failure indicate the design should lean on the gentle slope.
\end{abstract}

\section{Introduction}

Slope failures are one of frequent disasters happened, including man-made slopes. Man-made slopes exist all over the world for road constructions, dams, dykes, and other infrastructures. Most failures of man-made slopes, especially in road construction, are caused by design errors including geometry designs and inability to estimate soil strength parameters. This problem occurs typically due to inadequate soil investigations in the design phase, and therefore it may threaten the stability and economic values of the infrastructure during its engineering lifetime $[1,2]$. In designing slope, engineer is required to design the safest and most economically feasible one. However, in its practice, the increasing of safety usually resulted in the increasing of cost construction.

Traditionally, the engineer relies primarily on empirical factor of safety to reduce the risk or adverse performance (collapse, excessive deformation, etc.) to acceptable level. However, a larger factor of safety does not necessarily imply a smaller risk, because its effect can be negated by the presence of larger uncertainties in the design environment. It implies the relationship between FS and the underlying level of risk is not simple one [3]. The objective of this research is to examine the effect of slope design parameters (slope angle and height) and the uncertainty in soil strength on the slope design cost and its consequences using the decision-making analysis.

\section{Literature review}

\subsection{Reliability-based design}

Reliability analysis is defined as the consistent evaluation of design risk using probability theory. Reliability-based design (RBD) refers to any design methodology that applies reliability principles, explicitly or otherwise [3]. The basic goal of RBD is to adjust set of design parameter that a prescribed target of probability of failure not exceed the acceptable threshold level $[3,4]$. It is well accepted that uncertainties in geotechnical engineering design are unavoidable and numerous practical advantages are realizable if uncertainties and associated risks can be quantified [5]. In principle as one of the target of RBD lies in selection of an appropriate value of probability of failure $\left(\mathrm{P}_{\mathrm{f}}\right)$. A rational value of $\mathrm{P}_{\mathrm{f}}$ can be determined by conducting a cost-benefit analysis as show in Fig. 1, and the most economical target probability of failure would consider explicitly the variation of initial cost, maintenance cost, and expected failure cost with $\mathrm{P}_{\mathrm{f}}$.

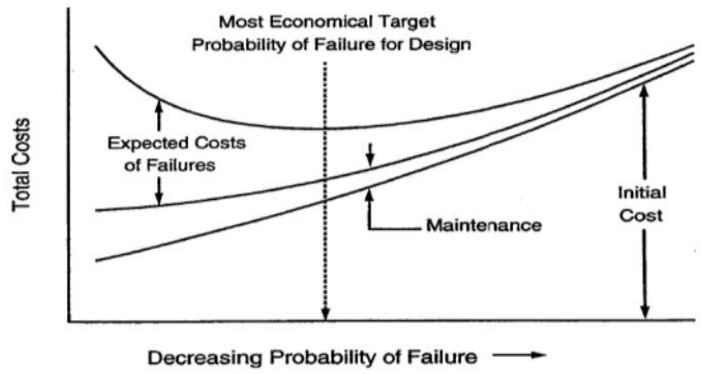

Fig. 1. Cost-Benefit Analysis in RBD [3]

\footnotetext{
* Corresponding author: hasnarifani@gmail.com
} 


\subsection{Uncertainty of soil parameters}

The overall uncertainty underlying a geotechnical design parameter results from many different sources of uncertainties such as natural (inherent) variability, measurement error, and transformation uncertainty. These uncertainty factors make the soil coefficient of variation higher than other materials [5]. Some studies of uncertainty in soil parameter [6] are as follow:

- COV for Specific Gravity is relative small, between $5 \%$ to $10 \%$. COV for moisture content vary from $10 \%$ to $25 \%$. The COV for soil porosity is $10 \%$ up to $30 \%$.

- Uncertainty in shear strength parameter, compression index and consolidation index is relatively large, vary from $5 \%$ to $50 \%$.

- Uncertainty of soil properties in field testing is greater that laboratory testing.

- Soil parameter generally follow normal and lognormal distribution.

\subsection{Probabilistic assessment}

In slope stability analyses, the Finite Element Method (FEM) or the Limit Equilibrium Method (LEM) are commonly used. However, these deterministic methods do not address explicitly the uncertainty of soil parameters. Thus, the probabilistic approach needs to be introduced in the reliability-based design [7]. The probabilistic approach and reliability analysis method provide a rational way to account the uncertainties from different sources and estimate the probability of satisfactory performance in systematic way. It incorporates wide range of data, and uncertainties are taken into account. The Monte-Carlo simulation method is commonly used in reliability analysis used for wide range of problems in geotechnical engineering. The Monte-Carlo simulation method is used to get the probability density function of output variable, such as safety factor, percentage of probability of failure and reliability index, from random variable distribution of shear strength parameter, represented in distribution functions [7].

In this research, software SLOPE/W is used. The software is capable of accommodating the Monte-Carlo simulation method. The uncertain parameters taken into account are the unit weight and shear parameter (cohesion and friction angle).

\subsection{Decision making analysis}

Decision making analysis consists of framework and toolkit for dealing with difficult decision making processes, and when carefully applied, this analytical technique would lead decision makers to make better decisions. Decision making analysis not only provide structured way of think about decision, but more fundamentally it provides the required structure within. The purpose of decision making analysis is to help a decision maker to think systematically about complex problems and improve the quality of resulting decision [8].
In modelling decision making there are three fundamental process:

1. Identifying and structuring values \& objectives

2. Structuring element of decision to logical framework

3. Refining and precising definition of all elements of decision making.

The fundamental process above helps decision maker in structuring various decision elements, taken consideration of every element and alternatives, and uncertain event with its outcomes and resulting consequences into a simple representative diagram of the complex decision making situation such as a decision tree. A decision tree helps decision makers determine the sequence of the decision taken. The sequences of decision are derived from the considered factor of uncertainty and the output result. the Expected Monetary Value (EMV) is commonly used in decision making to calculate the monetary expectation rather as a cost or profit for each decisions. The typical decision tree used in the reliability based design in geotechnical engineering is as shown in Fig. 2.

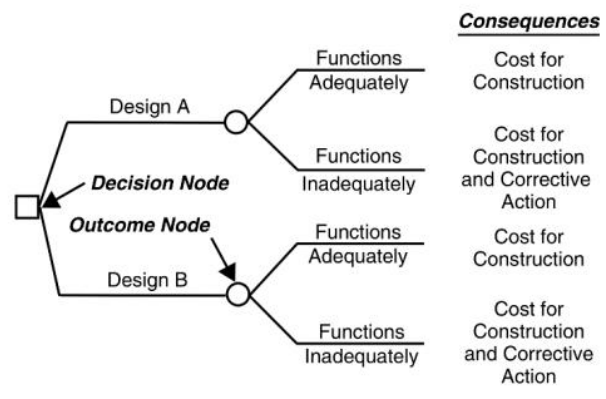

Fig. 2. Decision Tree used in RBD [4]

\section{Research method}

\subsection{Soil parameters and slope geometry}

The assumed soil condition in this study is homogenous silty clay material in type of tropical red clay. The shear parameters are taken from Triaxial $\mathrm{CU}$ data around Depok, West Java, and thy are distributed using the normal distribution function truncated from its mean value into $2 \sigma$ for cohesion parameter and $3 \sigma$ for friction angle parameter. The overall of parameters of tropical red clay used in this research is given in Table 1.

Table 1. Summary of soil parameters [13]

\begin{tabular}{|l|l|l|}
\hline \multirow{3}{*}{$\begin{array}{l}\text { Effective } \\
\text { Cohession }\end{array}$} & $c^{\prime}(\mathrm{kPa})$ & 27 \\
\cline { 2 - 3 } & COV & 44.94 \\
\cline { 2 - 3 } & $\begin{array}{l}\text { Standard } \\
\text { Deviation }(\sigma)\end{array}$ & 12.14 \\
\hline \multirow{3}{*}{$\begin{array}{l}\text { Effective } \\
\text { Friction Angle }\end{array}$} & $\phi\left(^{(}\right)$ & 23 \\
\cline { 2 - 3 } & COV & 23.49 \\
\cline { 2 - 3 } & $\begin{array}{l}\text { Standard } \\
\text { Deviation }(\sigma)\end{array}$ & 5.4 \\
\hline Soil Type & Silty Clay \\
\hline rwet & $18 \mathrm{kN} / \mathrm{m}^{3}$ \\
\hline
\end{tabular}


As for the slope geometry, the slope angles considered are 27, 34, 45 and 63 degrees, while the slope heights vary from $5 \mathrm{~m}, 10 \mathrm{~m}$ and $15 \mathrm{~m}$. The slope angles used are considered as typical of cut-off slope for road construction in Indonesia $[9,10]$. The model of the geometry is as shown in Fig. 3.

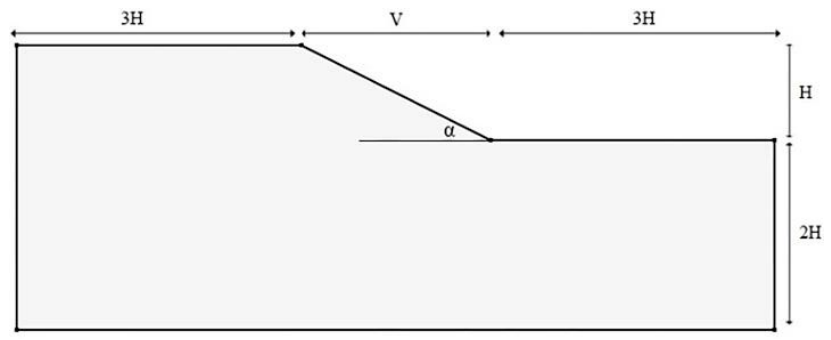

Fig. 3. Geometry Model

From Fig. 3, $\mathrm{H}$ is the height of the slope, $2 \mathrm{H}$ is the assumed elevation of hard soil, and V is the width of slope according to the angle of slope or $\alpha$. The ground water level at this research is not considered in the models as we focused on the uncertainty inherent in soil for the slope geometry design.

The SLOPE/W analyses are conducted using the entry-exit method, as the critical slip surface is unknown, which spans from point 1 to the middle of 2-3 for the entry range and middle point of 2-3 to 4 for the exit range as shown in Fig 4.

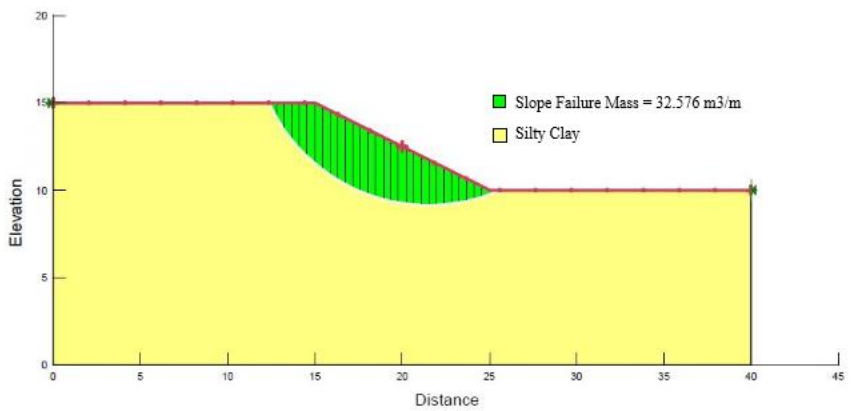

Fig.4. Slope Geometry and Failed Soil Mass Volume for 27 Slope Angle and $5 \mathrm{~m}$ Height

\begin{tabular}{|c|c|c|c|c|c|c|}
\hline $\begin{array}{l}\text { Height } \\
\text { (m) }\end{array}$ & $\begin{array}{l}\text { Slope } \\
\text { Angle } \\
\left({ }^{\circ}\right)\end{array}$ & $\begin{array}{c}\text { Cost } \\
\text { Construction } \\
(\text { IDR/m) }\end{array}$ & $\begin{array}{c}\text { Repairing } \\
\text { Cost (IDR/m) }\end{array}$ & $\begin{array}{c}\text { Indirect Loss } \\
\text { of LOS A } \\
\text { (IDR/m) }\end{array}$ & $\begin{array}{c}\text { Indirect Loss } \\
\text { of LOS B } \\
\text { (IDR/m) }\end{array}$ & $\begin{array}{c}\text { Indirect Loss } \\
\text { of LOS D } \\
\text { (IDR/m) }\end{array}$ \\
\hline \multirow{4}{*}{5} & 27 & $27,657,741.74$ & $36,903,712.44$ & $314,640,000$ & $692,208,000$ & $1,337,220,000$ \\
\hline & 34 & $25,949,867.08$ & $25,729,513.17$ & $209,760,000$ & $461,472,000$ & $891,480,000$ \\
\hline & 45 & $24,241,992.42$ & $25,254,832.52$ & $209,760,000$ & $461,472,000$ & $891,480,000$ \\
\hline & 63 & $22,534,117.76$ & $25,306,992.49$ & $209,760,000$ & $461,472,000$ & $891,480,000$ \\
\hline \multirow{4}{*}{10} & 27 & $109,856,890.23$ & $78,738,967.11$ & $629,280,000$ & $1,384,416,000$ & $2,674,440,000$ \\
\hline & 34 & $103,025,391.58$ & $63,459,379.86$ & $419,520,000$ & $922,944,000$ & $1,782,960,000$ \\
\hline & 45 & $96,193,892.94$ & $64,202,754.82$ & $419,520,000$ & $922,944,000$ & $1,782,960,000$ \\
\hline & 63 & $89,362,394.30$ & $55,610,940.00$ & $419,520,000$ & $922,944,000$ & $1,782,960,000$ \\
\hline \multirow{4}{*}{15} & 27 & $185,335,122.46$ & $130,631,630.87$ & $1,048,800,000$ & $2,307,360,000$ & $4,457,400,000$ \\
\hline & 34 & $169,964,250.52$ & $114,118,386.31$ & $943,920,000$ & $2,076,624,000$ & $4,011,660,000$ \\
\hline & 45 & $154,593,378.57$ & $118,424,495.77$ & $943,920,000$ & $2,076,624,000$ & $4,011,660,000$ \\
\hline & 63 & $139,222,506.63$ & $88,098,808.06$ & $524,400,000$ & $1,153,680,000$ & $2,228,700,000$ \\
\hline
\end{tabular}

\subsection{Decision tree model}

Construction projects are prone to uncertainty scenarios, in this case is the uncertainty in slope design. The decision tree is used as a tool in cost-benefit analysis in reliability based design of highway slope geometry. The cost analysis of highway geometry design derived from cost construction, repairing cost and indirect losses from highway closure.

From the SLOPE/W analysis, the probability of failure and the slope failure mass volume are obtained. The probability of failure used is the maximum probability of failure. Fig. 4 shows an example of failed soil mass volume for a slope with $5 \mathrm{~m}$ height and 27 degrees slope angle. The slope failure mass is then used to calculate the repairing cost. The probability of failure in each model is taken into consideration in the decision making analysis as the decision tree in Fig. 5 shows.

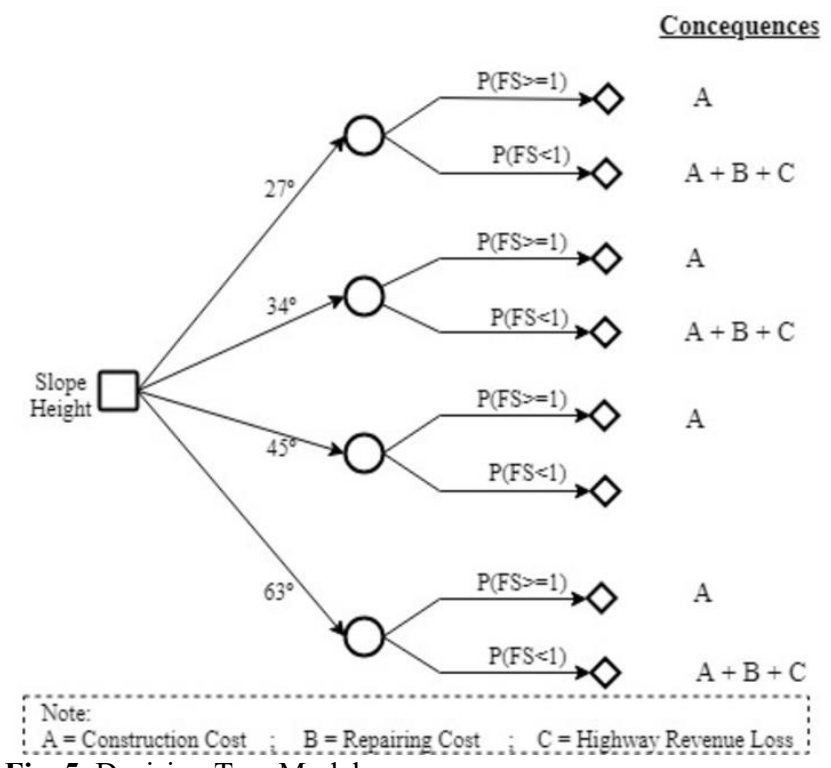

Fig. 5. Decision Tree Model 
In the cost analysis, the repairing cost and construction cost estimation can be calculated by multiply the quantity of work and the unit price. The unit price for each scope of work in the construction process used in this research is the unit price for Jakarta is used [11]. The estimation of the indirect loss from highway closure is obtained by calculating the revenue loss, derived from the Level of Service (LOS), and time (in days) to clean the failed soil mass volume. The summary of detailed costs used for the decision tree model in this research is shown in Table 2.

The revenue loss is assumed as the road is disabled during the slope failure. The loss is calculated by multiplying the toll entry fee (Jakarta outer Ring of Road entry fee assumed), and the vehicle volume of the road. The vehicle volume in this research is taken from the calculation of the traffic volume capacity by Level of Service. The traffic volume is calculated with road capacity analysis uses VCR method [12]:

$$
C=C_{o} \times F C_{w} \times F C_{s p}
$$

with $C=$ real capacity (veh/hour), $C o=$ basic capacity (veh/hour), $F c w=$ road with factor, $F C s p=$ Factor of separated way. The traffic volume capacity classified in level of service is taken into 3 types volume capacity as low volume capacity (LOS A), moderate (LOS B) and high capacity (LOS D). The overall traffic volume capacity by Level of service classification used in this research based on authors' study is as shown in Table 3 .

Table 3. Summary of Traffic Volume Capacity by LOS and its Revenue Loss

\begin{tabular}{|c|c|c|}
\hline $\begin{array}{c}\text { Level of } \\
\text { Service }\end{array}$ & $\begin{array}{c}\text { Traffic Volume } \\
\text { Capacity (veh/day) }\end{array}$ & $\begin{array}{c}\text { Revenue Loss } \\
\text { (IDR/per day) }\end{array}$ \\
\hline A & 11040 & $104,880,000$ \\
\hline B & 24288 & $230,736,000$ \\
\hline D & 46920 & $445,740,000$ \\
\hline
\end{tabular}

\section{Results and analysis}

\subsection{Slope geometry and probability of failure}

The change of slope's probability of failure for each slope angle and height is reviewed. The result is shown as Fig. 6.

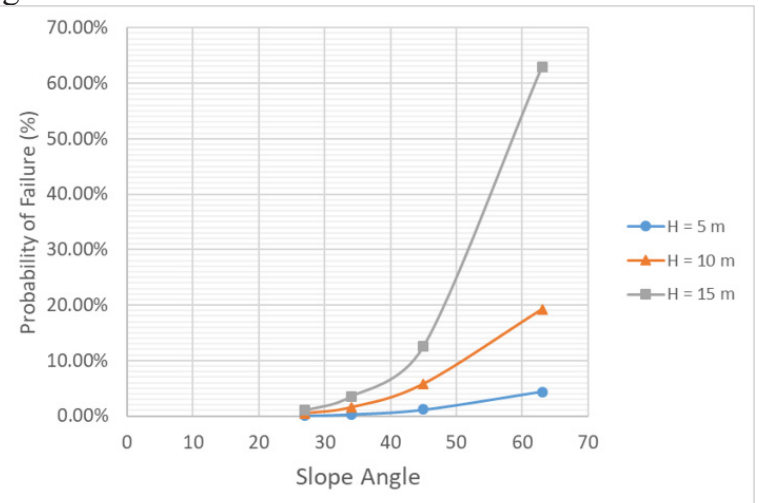

Fig. 6. Probability of Failure for different angle at $5 \mathrm{~m}, 10 \mathrm{~mm}$ and $15 \mathrm{~m}$ height

\footnotetext{
* Corresponding author: hasnarifani@gmail.com
}

Fig. 6 shows that the probability of failure increases with an increase in slope angle. It also shows that the higher slopes would have higher probability of failure. For slopes with greater than $10 \mathrm{~m}$ height, the probability of failure for 45 and 63 degrees slope angle is greater than $10 \%$. The probability of failure for 63 degrees slope angle in $15 \mathrm{~m}$ height is exceed $50 \%$, indicating the likelihood of slope failure. This indicates that the recommended slope design for height greater than 10 is constructed under 63 cut-slope angle.

\subsection{Decision making analysis}

\subsubsection{No LOS considered}

As previously discussed, the result indicates that steeper slopes would have greater slope probability of failure. The probability of failure for each geometry is then used in the quantitative decision making analysis. The results of decision making analysis are shown in Fig. 7.

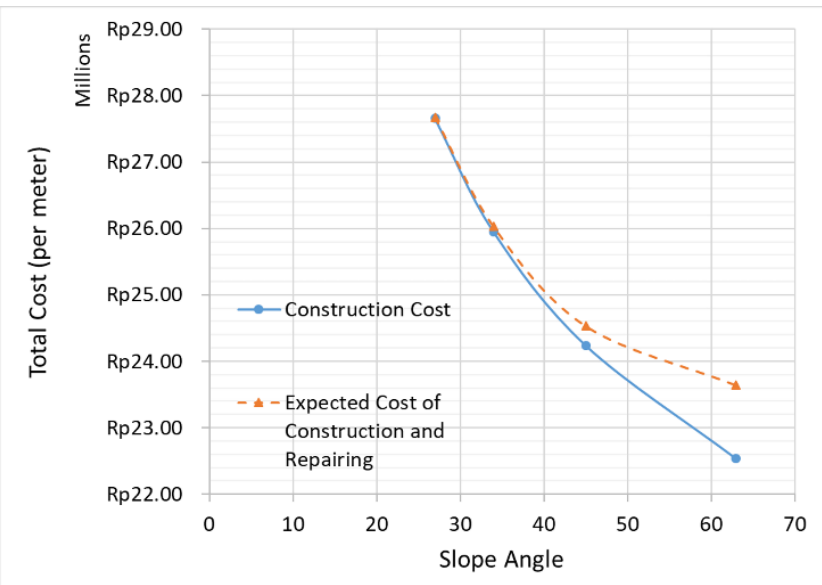

(a)

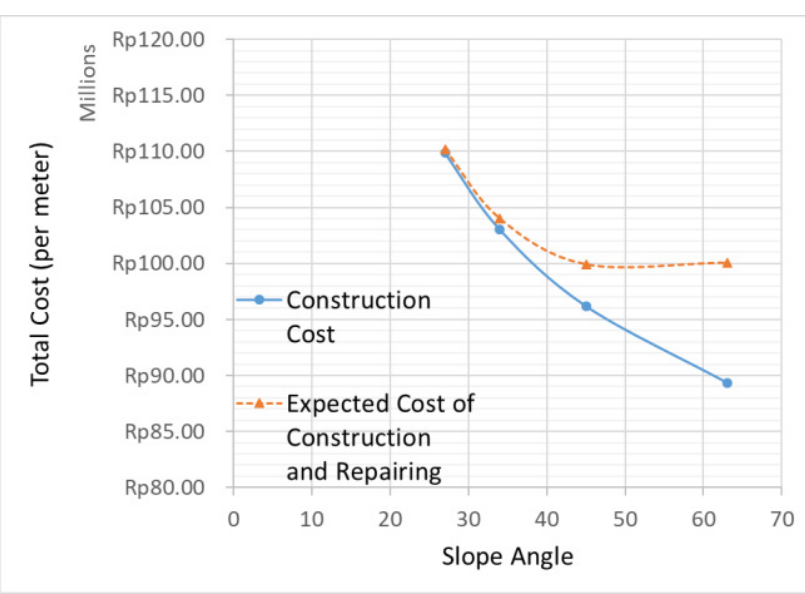

(b) 


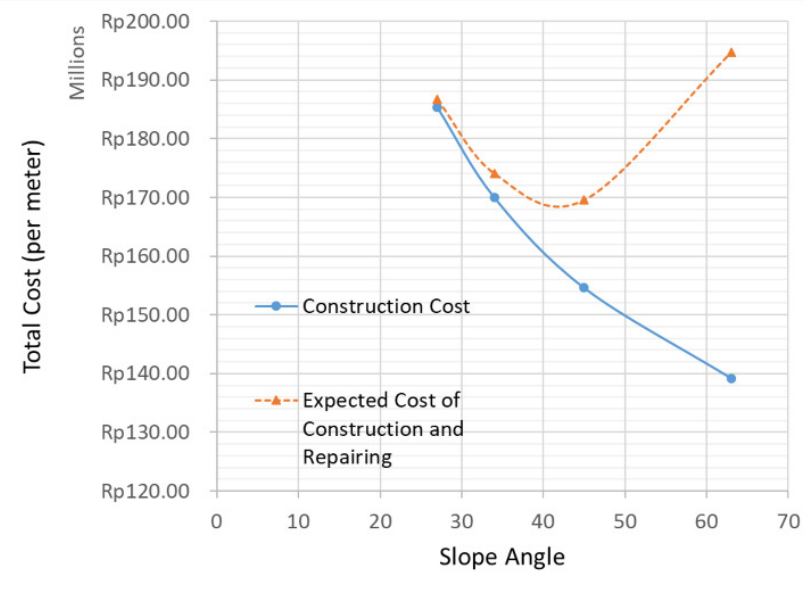

(c)

Fig. 7. Expected cost of design slope based on earthwork construction and repaiiring cost at (a) $5 \mathrm{~m}$ height slope, (b) 10 $\mathrm{m}$ height slope, (c) $15 \mathrm{~m}$ height slope

Fig. 7 shows that, when only the construction and repairing costs considered, steeper slopes are in general economically feasible. The only exception would be for a $15 \mathrm{~m}$ height, 63 degree slope. For this slope, the probability of failure would be greater than $15 \%$.

\subsubsection{Risk for roads with LOS A classification (low traffic capacity)}

Fig. 8 through 10 show the total EMV for slope heights of $5 \mathrm{~m}, 10 \mathrm{~m}$, and $15 \mathrm{~m}$, respectively, for low volume capacity roads (LOS A). For $5 \mathrm{~m}$ high slopes, it appears that 45 degrees slope angle would be most economically feasible. The most feasible slope angle tends to decrease as the slope height increases.

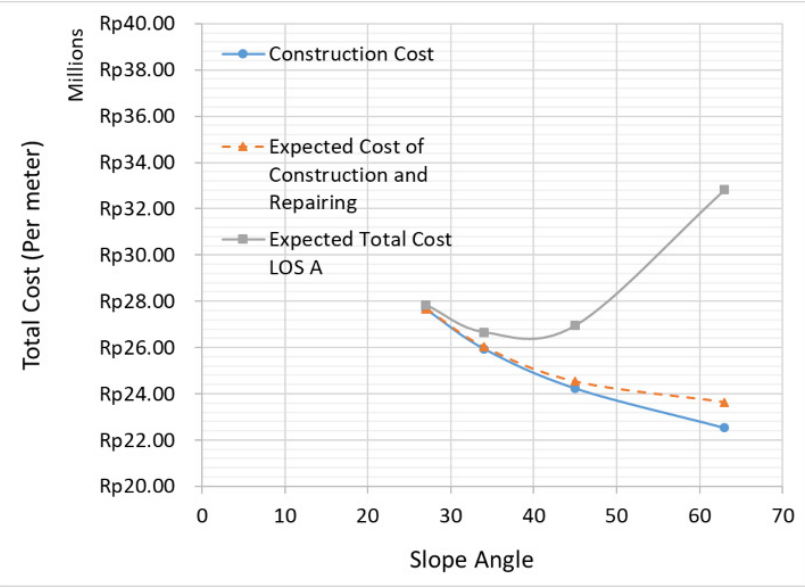

Fig. 8. Expected Total Cost with risk of highway classification as LOS A classification for each angle at $5 \mathrm{~m}$ height

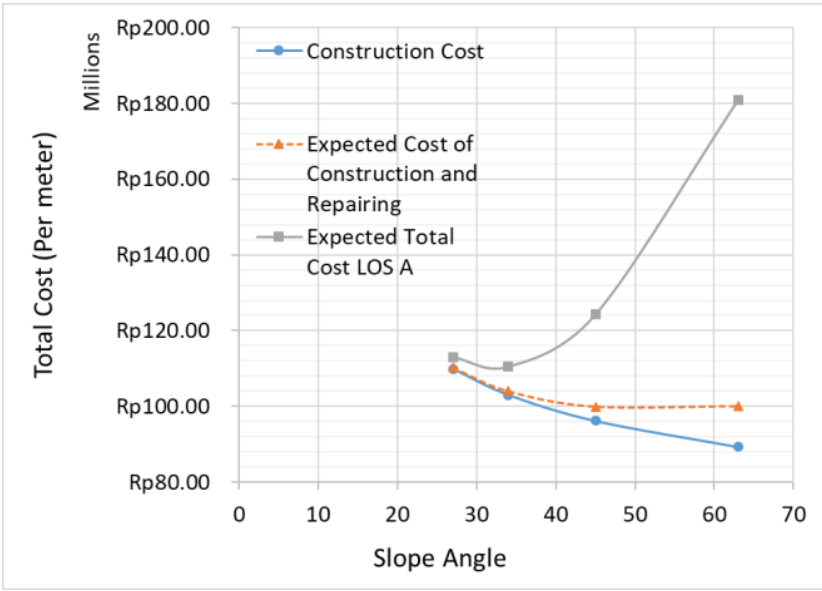

Fig. 9. Expected Total Cost with risk of highway classification as LOS A classification for each angle at $10 \mathrm{~m}$ height

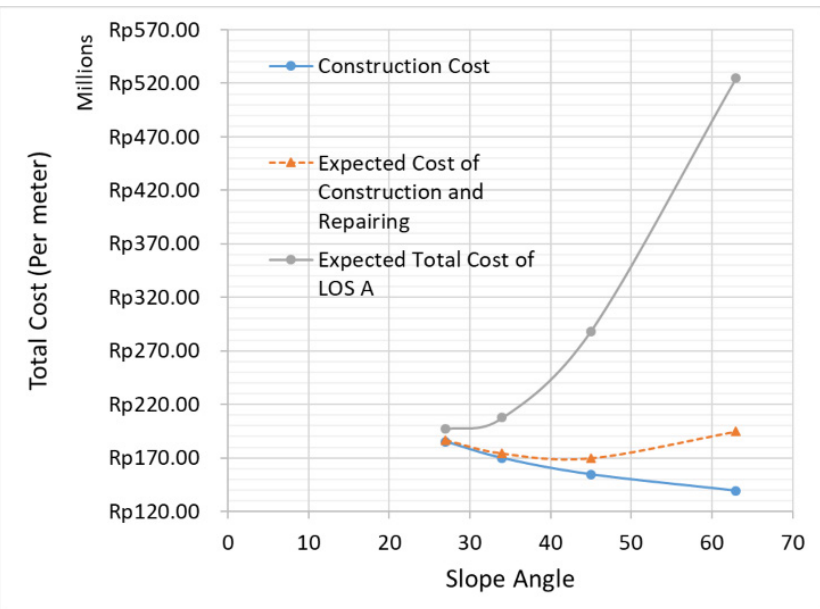

Fig. 10. Expected Total Cost with risk of highway classification as LOS A classification for each angle at $15 \mathrm{~m}$ height

\subsubsection{Risk for roads with LOS B Classification (moderate traffic capacity)}

Fig. 11 through 13 show the total EMV for slope heights of $5 \mathrm{~m}, 10 \mathrm{~m}$, and $15 \mathrm{~m}$, respectively, for moderate volume capacity roads (LOS B). For $5 \mathrm{~m}$ high slopes, it appears that about 35 degrees slope angle would be most economically feasible. The most feasible slope angle tends to decrease as the slope height increases. 


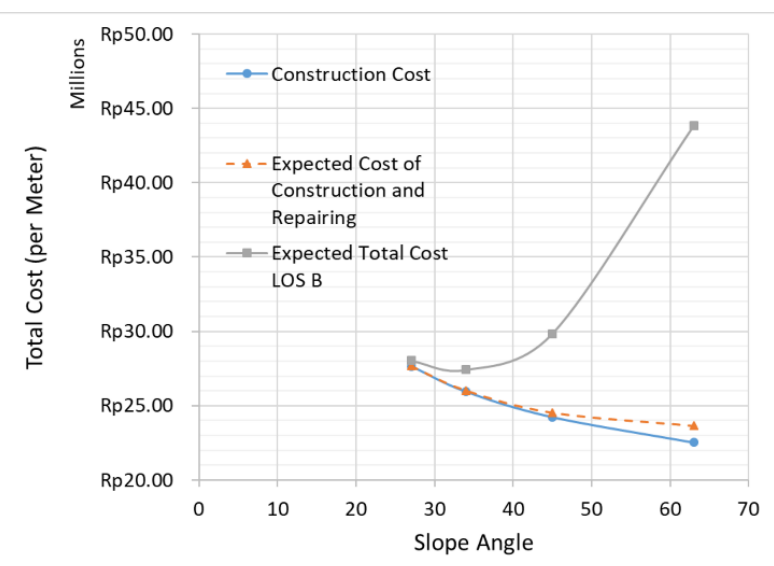

Fig. 11. Expected Total Cost with risk of highway classification as LOS B classification for each angle at $5 \mathrm{~m}$ height

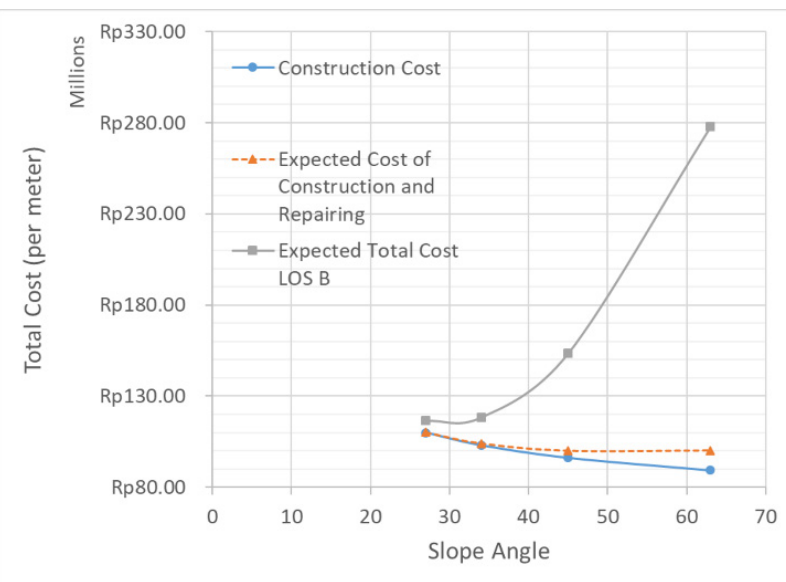

Fig. 12. Expected Total Cost with risk of highway classification as LOS B classification for each angle at $10 \mathrm{~m}$ height

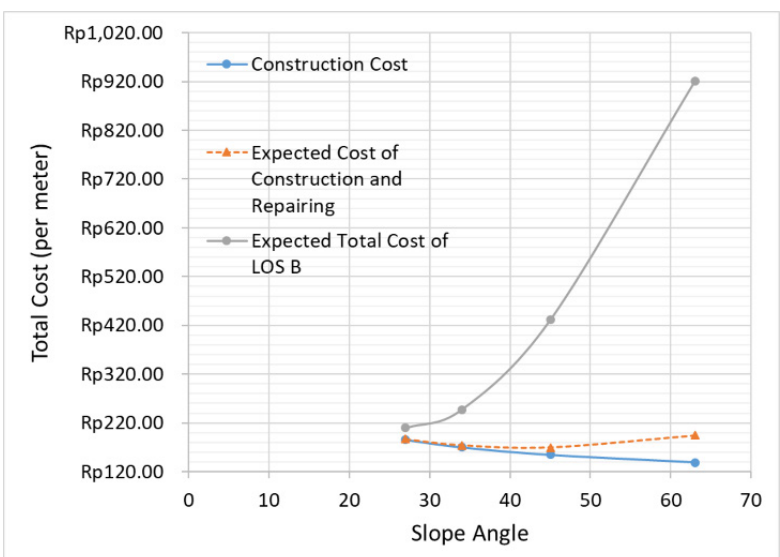

Fig. 13. Expected Total Cost with risk of highway classification as LOS B classification for each angle at $15 \mathrm{~m}$ height.

\subsubsection{Risk for roads with LOS D Classification (high traffic capacity)}

Fig. 14 through 16 show the total EMV for slope heights of $5 \mathrm{~m}, 10 \mathrm{~m}$, and $15 \mathrm{~m}$, respectively, for high volume capacity roads (LOS D). For $5 \mathrm{~m}$ high slopes, it appears that less than 35 degrees slope angle would be most economically feasible. The most feasible slope angle tends to decrease as the slope height increases.

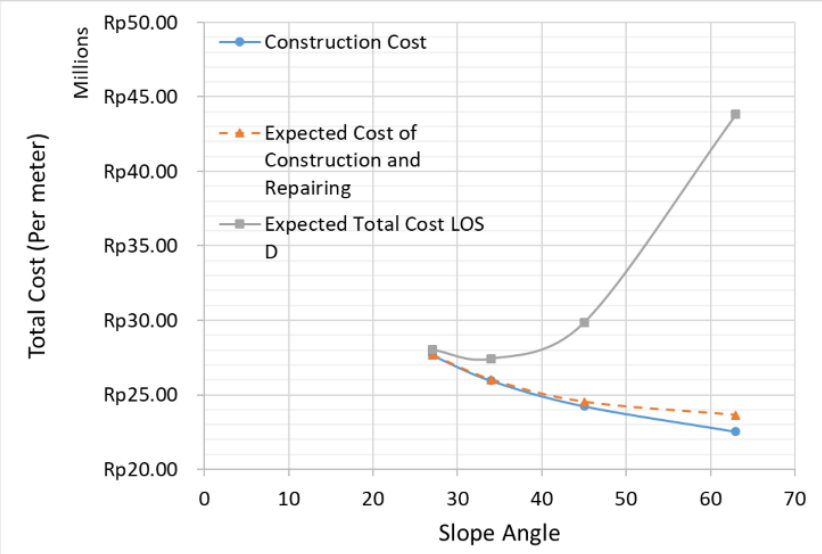

Fig. 34. Expected Total Cost with risk of highway classification as LOS D classification for each angle at $5 \mathrm{~m}$ height

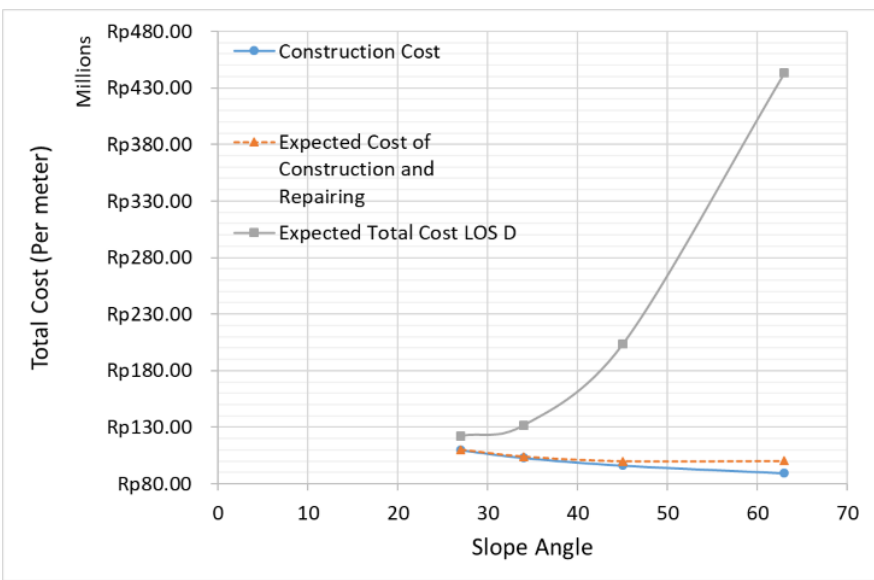

Fig. 45. Expected Total Cost with risk of highway classification as LOS D classification for each angle at $10 \mathrm{~m}$ height

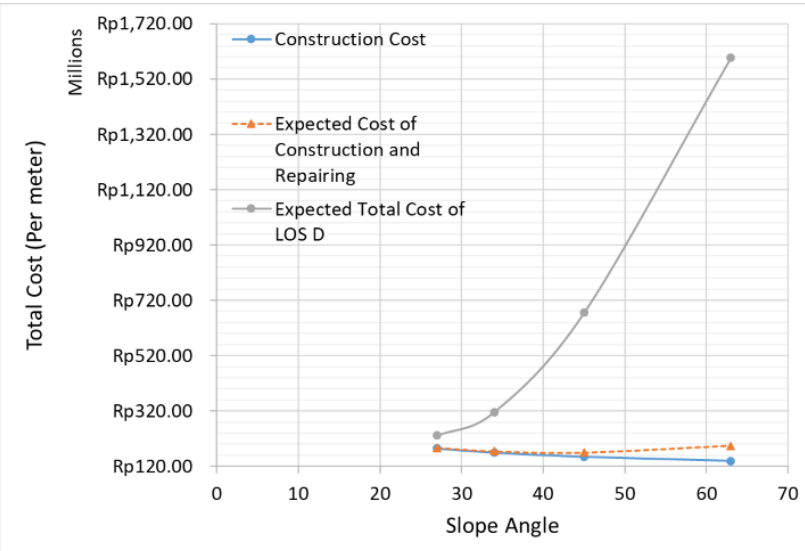

Fig. 16. Expected Total Cost with risk of highway classification as LOS D classification for each angle at $15 \mathrm{~m}$ height

\subsubsection{Discussions}

It can be observed that the level of services would affect the decision making. This was represented by the lowest the total EMV of the design alternatives. The comparisons among Figs. 7-9, Figs. 10-12, and Figs. 13-15, indicate that the difference in level of service would affect the slope design decision. For greater traffic volume of the highway, the roads would have higher risk of loss of 
revenues. Overall, the most economically feasible slope design would be relatively gentle slopes of about 27-34 degrees. Furthermore, for greater slope heights, the most economically feasible slope angles would lower.

\section{Conclusions}

The findings from this research are summarized as follows:

1. Probabilistic approach using Monte-Carlo simulation method in slope stability is often used to solve the uncertainty problem, especially for a wide range of data. In this study, this approach is used in the decision making analysis to calculate the probability of the alternatives and show the outcome for each alternatives. The probabilistic approach based on this parametric data shows that the steeper slope angles the bigger probability of failure possessed by design.

2. Based on this study, the probability of failure for slope with 63 degrees slope angle is greater than $10 \%$ for $10 \mathrm{~m}$ and $15 \mathrm{~m}$ height, indicating recommended cut-off slope angle of lower than 63 degrees. Different parametric data would indicate a different recommended angle in same pattern of result.

3. Based on decision making analysis, the cost of earthwork nor the construction cost would not affect the EMV much, thus steeper slopes would be feasible as the best decision, even for high probability of failure. However, as the consequences of the design alternatives are taken into the consideration, the minimum total EMV shifted into the gentle slope angle. Noted that this study indicate that the EMV is affected by the probability of failure, thus the different parametric data used may resulted in different probability of failure for each slope angles.

4. For this homogenous slope design, the risk of different design alternatives, represented by the revenue loss for different level of service, would determine the highways slope angle design rather than the construction cost of the design alone. The cost of risk would represent significant difference in the decision made.

The authors gratefully acknowledge the part support provided through the research grant PUPT by Minister of Research, Technology, and Higher Education through Universitas Indonesia under the contract No 513/UN2.R3.1/HKP.05.00/2018.

\section{References}

1. Y. Sutejo \& N. Gofar, Effect of Area development on Stability of Cut Slopes, Procedia Eng. International Conference of Euro Asia Civil Engineering (EACEF5), 125, 331-337, Indralaya: Elsevier Ltd. (2015)

2. J. Rupke, M. Huisman, H.M. Kruse, Stability of ManMade Slopes, Eng. Geol., 91, 16-24, (2007)

3. K. K. Phoon, F. Kulhawy, M.D. Grigoriu, ReliabilityBased Design of Foundation for Transmission Line Structure (Cornell University, Geotechnical
Engineering. Ithaca, New York: Electric Power Research Institue. 1995)

4. K. K. Phoon, J. V. Retief, Reliability of Geotechnical Structure in ISO2394 (CRC Press, 2016)

5. K. K. Phoon, Reliability-Based Design in Geotechnical Engineering (Taylor \& Francis, 2008)

6. L. Zhang, J. Li, X. Li, J. Zhang, H. Zhu, Rainfallinduced soil slope failure: stability analysis and probabilistic assessment (CRC Press: Taylor \& Francis Group, Boca Raton, 2016)

7. T. Chaulagai, A. Osouli, J. Clemente, Probabilistic Slope Stability Analysis-A Case Study, ASCE, Geotechnical Frontiers 2017: Walls and Slope, 444452. (2017)

8. Robert T. Clemen, Making Hard Decision, Second Edition. (United States of America: Duxbury Press, 1996)

9. Ministry of Public Works (PU), Perencanaan teknis lereng galian pada material vulkanik dan tanah residual (2015)

10. Ministry of Public Work (PU), Pedoman Bahan Konstruksi Bangunan dan Rekayasa Sipil: Mitigasi Tingkaat Resiko Lereng Jalan, (to be published)

11. Ministry of Public Work (PU), Pedoman Analisis harga Satuan Pekerjaan Bidang Pekerjaan umum. (2013)

12. Directorate General Bina Marga Directorate of Urban Road Development, Manual Kapasitas Jalan Indonesia (1997)

13. Fathiyah H. Sagitaningrum, Widjojo A. Prakoso, Erly Bahsan, Probabilistic Analysis of Cut-Slope Stability for Tropical Red Clay of Depok, West Java as an Effect of Rainfall Duration and Intensity, MATEC Web Conf. 147, (2018) 